\title{
Assessment of the Mechanical Properties of Orthopedic Screws Coated with Polyurethane Acrylate Containing Hydroxyapatite, Intended to Fix the Fragility Fractures
}

\author{
ALEXANDRU FILIP ${ }^{1}$, OVIDIU ALEXA ${ }^{1 *}$ PAUL DAN SIRBU ${ }^{1 *}$, CRISTIANA FILIP $^{2 *}$, LIVIU ANDRUSCA $^{3}$, IONUT, $-A L I N$ PASCAL ${ }^{4}$, \\ STEFAN OPREA ${ }^{5}$, OANA VIOLA BADULESCU ${ }^{6}$ \\ ${ }^{1}$ Grigore T. Popa University of Medicine and Pharmacy, Faculty of Medicine, Department of Orthopedics and Traumatology Surgical Sciences (II), \\ 16 Universitatii Str., 700115, Iasi, Romania \\ ${ }^{2}$ Grigore T. Popa University of Medicine and Pharmacy, Faculty Of Medicine, Department of Biochemistry, Morpho-functional Sciences (II), \\ 16 Universitatii Str., 700115, Iasi, Romania \\ ${ }^{3}$ Gheorghe Asachi Technical University, Faculty of Mechanical Engineering, Department of Mechanical and Automotive Engineering, 43 Profesor \\ Dimitrie Mangeron Blvd., 700050, Iasi, Romania \\ ${ }^{4}$ Gheorghe Asachi Technical University, Faculty of Mechanical Engineering, Department of Mechatronics and Robotics, 51 Profesor Dimitrie \\ Mangeron Blvd., 700050, Iasi, Romania \\ ${ }^{5}$ Institute of Macromolecular Chemistry „Petru Poni”, Department of Polyadition and Photochemistry, 41A Aleea Grigore Ghica Vodă, 700487, Iasi, \\ Romania \\ ${ }^{6}$ Grigore T. Popa University of Medicine and Pharmacy, Faculty of Medicine, Department of Pathophysiology, Morfo-Functional Sciences (II), \\ 16 Universitatii Str., 700115, Iasi, Romania
}

The fragility fracture fixation confronts with the major problem of implant loosening due to the altered bone structure. Techniques used to fragility fracture stabilization includes metals devices, cements or adhesives. Different types of cements and adhesive can be obtained by chemical manipulation in order to provide a more efficient transition between the metal surface and the real bone. Thus, by selecting the appropriate chemical composition and ration between the components, synthetic cement and adhesive can provide a proper interface that ensure a perfect cohesion between the implant material and the natural bone. Most of the studies point the benefit of these synthetic materials in improving screw fixation strength. That is why, currently, the synthetic materials used in prosthesis are improved by associating with natural components of the bone, such as hydroxyapatite. For osteoporosis, which is characterized by demineralization, the association of the implanted material with hydroxyapatite is expected to be a suited solution for bone matrix regeneration after implantation. The aim of the current study was to assess the mechanical properties of orthopedic screws coated with a new polyurethane acrylate polymer containing hydroxyapatite in order to improve the stability of the screw for the subsequent fixation of the fragility fracture. To test the efficiency of the new hydroxyapatite containing polymer, the mechanical behavior of the coated screws was evaluated. Our data show that the augmented screw can be obtained by incorporating lower hydroxyapatite concentrations.

Key words: polyurethane acrylate, hydroxyapatite, fragility fracture, osteoporotic fixation

Nowadays bone injury is a wide spread pathology caused by either trauma or bone-related diseases. Within bone-related diseases the osteoporosis represents a significant percentage due to the increased age of population. The risk of a fracture is highly elevated in osteoporosis due to the altered structure of the bone. In the particular case of the osteoporosis fracture, also known as fragility fracture (FF) the implant loosening is frequently noticed. Techniques used to stabilize the fragility fractures includes metals devices, cements or adhesives [1-3]. Most of the studies point the benefit of these synthetic cements or adhesives in improving implants fixation strength [4] but also warn about the shortcomings: mismatch in stiffness between the cement and the contiguous bone, necrosis, thrombosis [5-8]. In the fragility fracture of the pelvis (FFP) due to its localization the therapeutically approach becomes more difficult. For this reason, fragility fractures fixation associate implants with the administration of drugs that stimulate bone recovery such as calcium, vitamin $\mathrm{D}$, anti-resorption or anabolic agents [9.]. Lately, metallic or polymeric implants have been associated with hydroxyapatite (HA), which is a natural component found in bone [10,11]. Hydroxyapatite belongs to the calcium phosphates group. It had been shown to be most suitable for prosthetic devices because it is similar to bone structure, promotes the osteointegration and bone-healing process [12]. In addition, it has low toxicity and is successfully used in the form of scaffolds or coatings for orthopedic

*email: ovidiu_alexa@yahoo.com;pdsirbu@yahoo.com; cfilip2000@yahoo.com 
applications [13]. Due to its chemical stability and excellent biocompatibility the orthopedic community use HA for bone defect augmentation [14].

In our previous work [15], we had studied the improvement of the orthopedic screw fixation by covering it with a particular polyurethane, namely acrylic polyurethane (PUA). Our data showed a better adhesion between the metal device and the synthetic bone samples after PUA coating. The elastic properties of the PUA polymer absorb some of the tensile force thus increasing the resistance of the joint. We continue our previous study by incorporating hydroxyapatite into the PUA structure in order to confer to the coating material a structure closer to that of the natural bone. The aim of the study was to evaluate the influence of HA on implant stability using orthopedic screws coated with PUA containing different concentrations of HA. The screws coated with the new hydroxyapatite-polymers (PUA-HAs) were used to fix artificial osteoporotic bone samples and the mechanical properties of the joints were assessed. Obtained data show that the best mechanical resistance was obtained for the malleolar screw coated with polyurethane acrylate polymer containing $10 \%$ hydroxyapatite. The study envisages the future use of the augmented screw for the fixation of the fragility fracture of the pelvis.

\section{Experimental part}

The experiment contains two phases: first, the synthesis of the polyurethane acrylate polymer containing two concentrations of hydroxyapatite: 10\% (PUA-10\%HA) respectively 30\% (PUA-30\%HA) and second, the mechanical testing of orthopedic screws coated with these polyurethane acrylate containing hydroxyapatite fillers used to fix artificial blokes that simulate osteoporotic bone. Polymer synthesis. New hydroxyapatite-polymers were synthesized at the Institute of Macromolecular Chemistry "Petru Poni", Iasi, Department of Polyaddition and Photochemistry by incorporating different HA concentrations in the mass of the polyurethane acrylate polymer. The polyurethane acrylate polymer was previous tested for the capacity to augment orthopedic screw fixation on artificial osteoporotic bone [15]. In the present study we continue the previous research by trying to obtain a better compatibility to the bone matrix by incorporating hydroxyapatite into the PUA polymer mass. Hydroxyapatite was chosen due to its similarity to the bone structure, interfacial stability and good adhesion [16], osseointegration [17], osteoconduction [18] and osteoinduction [19].

\section{Mechanical tests}

Mechanical tests evaluate the behavior of the orthopedic titanium screws, covered with a PUA-HAs film, used to fix synthetic bone samples. Synthetic bone samples (Sawbones-SKU: 1522-09) simulating osteoporotic bone were 7.5 PCF cell polyurethane foam blocks (size $40 \mathrm{~mm} \times 130 \mathrm{~mm} \times 180 \mathrm{~mm}$ and density $0.16 \mathrm{~g} / \mathrm{cm}^{3}$ similar to osteoporotic density). The titanium screws (Biomatrix) have two different diameters: HB 6.5 malleolar screw and HB 6.5 cancellous screw, length 60$70 \mathrm{~mm}$. In order to evaluate the benefits of incorporating HA into the polymer, screws coated with polymers containing different hydroxyapatite concentrations were subjected to tensile tests. Their mechanical behavior was compared with that of similar screws covered only with PUA. Tensile tests were performed by a static testing machine (WDW-50E) using a rate of $1 \mathrm{~mm} / \mathrm{min}$. The tensile forces and displacements were recorded by a specialized WDW Universal Testing Machine Measure \& Control System program.

\section{Results and discussions}

The new hydroxyapatite polyurethane acrylate polymer was obtained by mixing hydroxyapatite with an aqueous solution of polyurethane acrylate which by strongly stirring generates a stable suspension of hydroxyapatite in PUA. The fixation of hydroxyapatite into the polymer mass is stabilized by the hydrogen bonds formed with different active groups belonging to the polyurethane such as the amide, urethane and hydroxyl groups (fig.1).

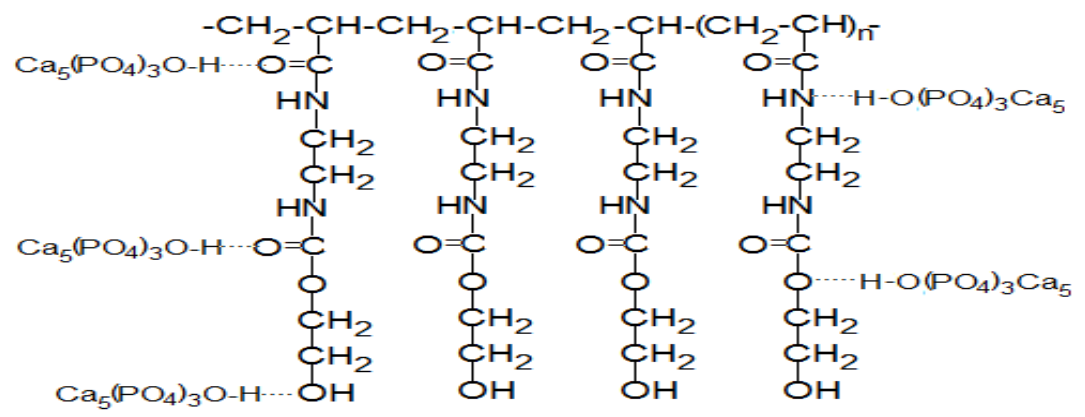

Fig.1 Hydrogen bonds formed between hydroxyapatite and PUA 
In addition, in the case of a real bone, both acrylate polyurethane and hydroxyapatite can form a significant number of strong physical bonds (hydrogen bonds, van der Waals, etc.) with the active groups from collagen belonging to the bone matrix, thus promoting an intimate connection to the implant (fig 2).

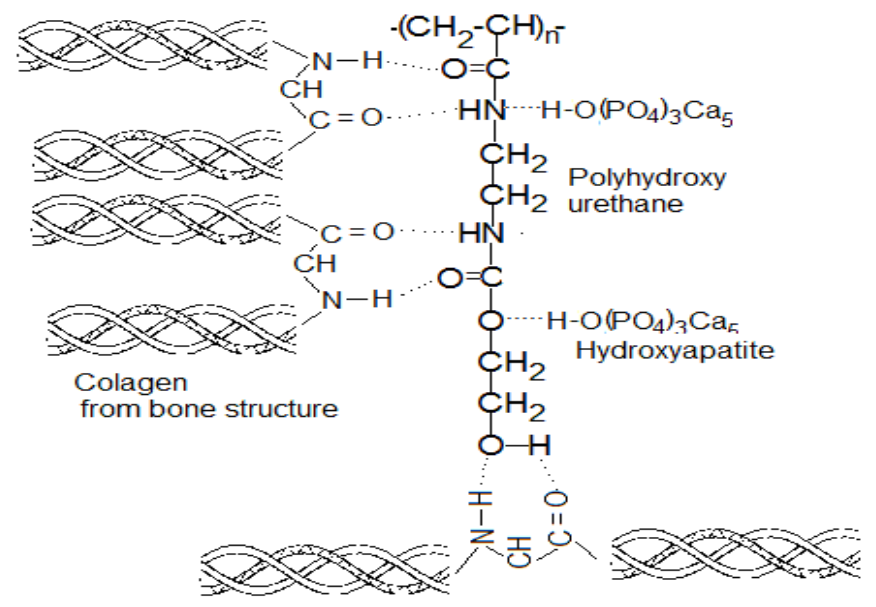

Fig.2. Hydrogen bonds that can be achieved within the matrix of polyhydroxy urethane, collagen fibers from bone structure and hydroxyapatite

The bone matrix is composed of organic components, such as elastic collagen fibers, as well as inorganic mineral components such as hydroxyapatite and calcium phosphate [20]. Collagen provides resistance to fracture due to its elasticity $[21,22]$ and inorganic mineralization ensures bone rigidity [23]. Thus, the combination of the biocompatible, strongly hydrophilic and elastic PUA, with the rigid hydroxyapatite, component belonging to the natural bone, brings together the elements required for an appropriate orthopedic cementation material.

In the case of the pelvis fracture, literature [24] indicate the tensile test as being the most relevant experiment for the bio-mechanical assessment. Joints behavior was evaluated in terms of maximum tensile forces and displacements. Results are presented in table 1.

Table 1

MAXIMUM TENSILE FORCES AND DISPLACEMENTS DETERMINED FOR THE ORTHOPEDIC SCREWS

\begin{tabular}{|l|c|c|c|c|c|}
\hline & \multicolumn{2}{|c|}{ PUA coating } & \multicolumn{2}{c|}{ PUA-10\% HA coating } & \multicolumn{2}{|c|}{ PUA-30\%HA coating } \\
\hline & $\begin{array}{l}\text { Maximum force } \\
(\mathrm{N})\end{array}$ & $\begin{array}{l}\text { Displace-ment } \\
(\mathrm{mm})\end{array}$ & $\begin{array}{l}\text { Maximum force } \\
(\mathrm{N})\end{array}$ & $\begin{array}{l}\text { Displace-ment } \\
(\mathrm{mm})\end{array}$ & $\begin{array}{l}\text { Maximum } \\
\text { force }(\mathrm{N})\end{array}$ \\
\hline $\begin{array}{l}6.5 \mathrm{~mm} \\
\text { malleolar } \\
\text { screw }\end{array}$ & $1.100 \pm 0.014$ & $10.82 \pm 0.05$ & $1.670 \pm 0.09$ & $11.625 \pm 0.38$ & $1.170 \pm 0.03$ \\
\hline $\begin{array}{l}6.5 \mathrm{~mm} \\
\text { cancellous } \\
\text { screw }\end{array}$ & $1.280 \pm 0.016$ & $12.44 \pm 0.17$ & $1.287 \pm 0.03$ & $11.816 \pm 0.50$ & $1.220 \pm 0.03$ \\
\hline
\end{tabular}

Under the conditions of PUA-10\% HA coating, obtained data show that the malleolar screws have a significant higher tensile force as comparing to similar screws covered only with the polyurethane acrylate. For the cancellous screw, under similar coating, the strength increase is not significant as comparing to similar screws covered only with PUA. These data suggest that adding $10 \%$ hydroxyapatite to the PUA improves the mechanical strength of the joint.

Under the conditions of PUA-30\% HA coating, both the malleolar and the cancellous screw present almost the same values for tensile forces compared to the similar screws covered only with PUA.

However, if comparing both screws covered with $10 \%$ HA versus those covered with $30 \% \mathrm{HA}$, it is noticed a significant resistance decreases, for the $30 \%$ HA coating. The results suggest that the high percentage of HA decreases the adhesion between the implant and the artificial bone. The increased presence of hydroxyapatite crystals probably introduces points of instability that disturb the cohesion of the entire joint consisting of polymer, screw and artificial bone.

Regarding the displacements for the malleolar screw, there is an increase for the both types of HA covering, compared to the screw covered only with PUA. The increase of displacements is significant in the PUA-10\% HA coating and not significant in the case of PUA-30\% HA coating. 
The data suggest that in the case of the malleolar screw, the $10 \%$ HA coating increases the displacement, allowing a greater deformation for a longer period of time before breaking.

In the case of the cancellous screw, there is a decrease of the displacement for both types of HA coating compared to the screw covered only with PUA. The displacement decrease is significant for the coverage with PUA-30\% HA. The data confirms the above assumption that a higher concentration of hydroxyapatite does not strengthen joint resistance, but rather disturbs it by introducing points or areas of instability.

As conclusion regarding the different HA concentrations, incorporated in the PUA, the best cohesion is obtained for the $10 \%$ hydroxyapatite concentration.

Regarding the two types of screws, the one that gained better mechanical properties after coating with PUA10\% HA is the malleolar screw.

The mechanical behavior for the malleolar screws coated with PUA only, PUA-10\% HA and PUA-30\% HA are presented in fig. 1, fig.2, and fig.3 respectively.

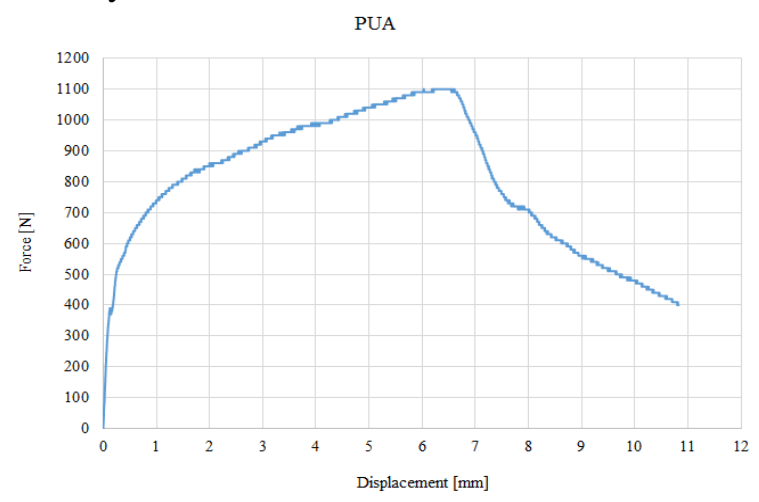

Fig.1. The $6.5 \mathrm{~mm}$ malleolar screw coated only with PUA mechanical testing

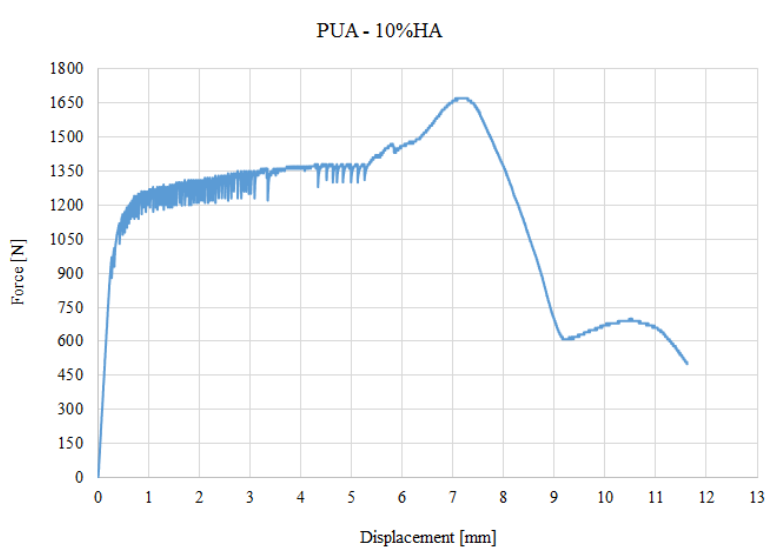

Fig.2. The $6.5 \mathrm{~mm}$ malleolar screw coated with PUA-10\%HA mechanical testing

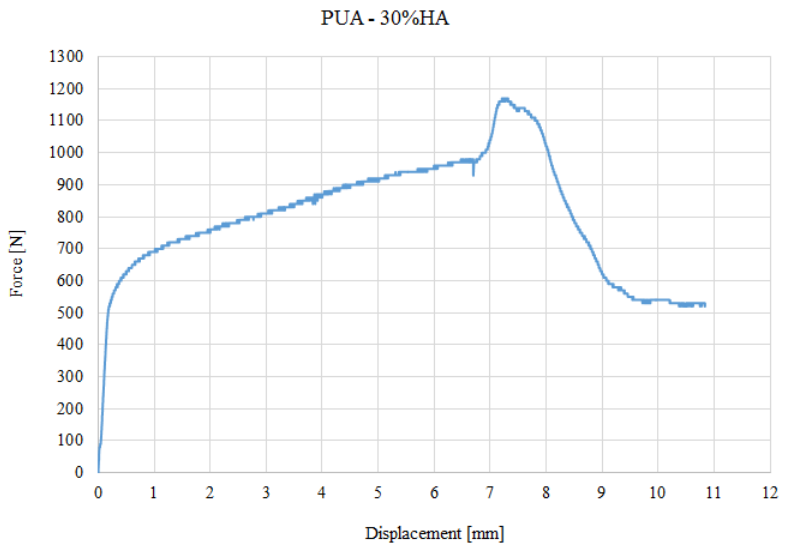

Fig. 3. The $6.5 \mathrm{~mm}$ malleolar screw coated with PUA-30\%HA mechanical testing

In our previous study [15] on improving the fixation of orthopedic screws by polymer coating, we obtained an increase of resistance for both malleolar and cancerous screws after PUA coating. If we add the results obtained in the previous study with the present one, we can conclude that, after different types of polymeric coatings, the best mechanical strength obtained, is for the malleolar screw with PUA-10\% HA coating $(1.670 \pm 0.09 \mathrm{~N}$ for coating PUA-10\% HA versus $1.060 \pm 0.012 \mathrm{~N}$ for uncoated screw) and for the cancellous screw covered only with PUA ( $1.280 \pm 0.03 \mathrm{~N}$ for PUA coverage versus $1.150 \pm 0.005$ $\mathrm{N}$ for uncoated screw).

\section{Conclusions}

In the particular case of fragility fractures, the main risk is the implant loosening due to the altered bone structure. For the FF fixation different synthetic materials whose characteristics can be chemically improved can be used. Our study show that augmented screw can be obtain by combining biocompatible polymers with hydroxyapatite. The appropriate ratio 
between the two components can provide a more efficient transition between the metal surface and the real bone. The incorporation of a component similar to the natural bone in the implanted device may be an important benefit in the case of the real bone due to the total compatibility between hydroxyapatite and the bone matrix. From this point of view the main limitation of the study is the use of the synthetic osteoporosis bone model.

\section{References}

1.JUVONEN, T., NUUTINEN, J.P., KOISTINEN, A.P., KROGER, H., APPALAINEN, R., Biomechanical evaluation of bone screw fixation with a novel bone cement, Biomed Eng Online, 14, 2015, p.74.

2.O. ALEXA, MIHAELA PERTEA, R.I. MALANCEA, B. PUHA, B. VELICEASA. Our experience in the surgical treatment of acetabular fractures using ,spring plate” technique. Med. Surg. J. - Rev. Med. Chir. Soc. Med. Nat., Iaşi 2019, 123(2):275-281.

3.PERTEA M, VELENCIUC N, GROSU O, VELICEASA B, POROCH V, LUNCA S. Reconstruction of heel soft tissue defect s using sensate medial plantar flap. J Mind Med Sci. 2018; 5(2): 250-254. DOI: 10.22543/7674. 52.P250254

4.WÄHNERT, D., HOFMANN-FLIRI, L., SCHWIEGER, K., BRIANZA, S., RASCHKE, M.J., WINDOLF, M., Cement augmentation of lag screws: an investigation on bio-mechanical advantages, Arc Orthop Trauma Surg., 133, 2013, p.373.

5. GHEORGHEVICI, T.S., VELICEASA, B., PUHA, B., TOADER, S., ALEXA, I.D., ALEXA., O., Preoperative hemoglobin dynamics in patients with trochanteric fractures: a multivariate analysis. Rev. Chim. (Bucharest), 69, 2018, no. 11, p. 4220-4224

6.R.I. MALANCEA, E.R. GAVRILIUC, B. VELICEASA*, B. PUHA, D. POPESCU, O. ALEXA. Methodology of Three-dimensional Printing in Acetabular Fractures, Mat. Plast., 54, no. 3, 2017, p. 513-516

7.LIU, D., LEI, W., WU, Z.X., GAO, M.X., WAN, S.Y., FU, S.C., et al., Augmentation of pedicle screw stability with calcium sulfate cement in osteoporotic sheep: biomechanical and screw-bone interfacial evaluation. J Spinal Disord Tech., 24, 2011, p.235.

8.BADULESCU, O. V., CIOCOIU, M., FILIP, N., VERINGA, V.,The Efficiency of Substitutive Treatment with Moroctocog Alfa in Managing Hemostasis in Patients with Hemophilia A Without Inhibitors With Total Knee Arthroplasties. Rev. Chim. (Bucharest), 69, no.12, 2018 , p.3702.

9.FILIP, A., VELICEASA, B., PUHA, B., FILIP, C., POPESCU, D., ALEXA, O., Bisphosphonates Influence and Pain Assessment in Mobilization of Patients with Fragility Fracture of the PelvisRev. Chim. (Bucharest), 70, no. 3, 2019, p.1094.

10.GOMES, D.S., SANTOS, A.M.C., NEVES, G.A., MENEZES, R.R., A brief review on hydroxyapatite production and use in biomedicine, Cerâmica, 65, nr.374, 2019, p.282.

11.SIDIKI, H.A., PICKERING, K.L., MUCALO, M.R., A Review on the Use of Hydroxyapatite-Carbonaceous Structure Composites in Bone Replacement Materials for Strengthening Purposes, Materials (Basel), 11, nr. 10, 2018, p.1813.

12.ALBREKTSSON T., JOHANSSON C., Osteoinduction, osteoconduction and osseointegration. Eur. Spine J. 2001; 10(Suppl. 2):S96-S101.

13.ELIAZ, N., METOKI, N., Calcium Phosphate Bioceramics: A Review of Their History, Structure, Properties, Coating Technologies and Biomedical Applications, Materials (Basel), 10, nr.4, 2017, p.334.

14.SHEPPERD, J., Fifteen Years of Clinical Experience with Hydroxyapatite Coatings in Joint Arthroplasty, Springer, Epinette J.A., Manley M.T., editors, Paris, 2004. p. 3.

15.FILIP, A., BADULESCU, O.V., SIRBU, P.D., VELICEASA, B., PUHA, B., PASCAL I.A., ANDRUSCA, L., OPREA, S., FILIP, C., ALEXA, O., Preliminary investigation on mechanical properties of polymer coating screws for the future fragility fracture fixation, Mat. Plast., 56, no. 3, 2019, p. 559.

16.PULEO, D.A., NANCI, A., Understanding and controlling the bone-implant interface. Biomaterials, 20,1999 , p.2311.

17.SAMAVEDI, S., WHITTINGTON, A.R., GOLDSTEIN, A.S., Calcium phosphate ceramics in bone tissue engineering: A review of properties and their influence on cell behavior. Acta Biomater., 9, 2013, p.8037.

18.AMBARD, A.J., MUENINGHOFF, L., Calcium phosphate cement: Review of mechanical and biological properties, J. Prosthodont., 15, 2006, p.321.

19.SURMENEV, R.A., SURMENEVA, M.A., IVANOVA, A.A. Significance of calcium phosphate coatings for the enhancement of new bone osteogenesis-A review, Acta Biomater.,10, 2014, p.557.

20.CHOCHOLATA, P., KULDA, V., BABUSKA, V., Fabrication of scaffolds for bone-tissue regeneration. Materials, 12, 2019 , p.568.

21.GOLDBERGA, I., LI, R., DUER, M.J., Collagen structure-function relationships from solid-state NMR spectroscopy, Acc. Chem. Res., 51, 2018, p. 1621.

22.PAWELEC, K.M., BEST, S.M., CAMERON, R.E., Collagen: a network for regenerative medicine. J. Mater. Chem. B, 4, 2016 , p. 6484.

23.ZHANG, K., FAN, Y., DUNNE, N., LI, X., Effect of microporosity on scaffolds for bone tissue engineering, Regenerative Biomaterials, 5, nr. 2, 2018, p.115.

24.ZANETTI, E.M., BIGNARDI, C., AUDENINO, A.L., Human pelvis loading rig for static and dynamic stress analysis, Acta of Bioengineering and Biomechanics, 14, nr.2, 2012, p.61.

Manuscript received: 31.10.2019 
